\title{
In-Situ Microstructure Evolution Under Stress Using a Large-Chamber SEM
}

\author{
R. Woracek, ${ }^{*}$ S. Young,* D. Penumadu, ${ }^{*}$ and J. Frafjord** \\ * University of Tennessee, CEE Department, 223 Perkins Hall, Knoxville, TN 37996 \\ ** Y-12 National Security Complex, Oak Ridge, TN 37831
}

A large-chamber scanning electron microscope (LC-SEM by VisiTec) shown in Fig. 1a was used to investigate samples in-situ using a custom developed tensile testing system. The LC-SEM used in this research is equipped with the following: secondary electron detector, backscattered electron detector (4 quadrants), electron backscatter diffraction (EBSD), energy dispersive x-ray spectrometry (EDS), and variable pressure mode.

A vacuum-suitable mechanical testing system, developed by the authors (see Fig. 1b), with an axial force capacity of $90 \mathrm{kN}$ was fabricated to perform unique in-situ studies on metallic and polymeric composite samples. The testing system uses custom developed LabView based data acquisition and control software for performing both stress and strain controlled tests. In-situ SEM and TEM investigations are not novel concepts [1-2], but a key feature of this system is the ability of testing larger specimens having geometry and dimensions similar to those used in traditional mechanical testing laboratories. The LC-SEM eliminates the need for using artificially small specimens, reducing unwanted size effects associated with applied deformation on the microstructure.

Deformation mechanisms, such as twinning and slip, as well as other microscopic features, such as pores, impurities, and cracks were examined in-situ under tensile stress at desired magnifications ranging from $50 \mathrm{X}$ to $20,000 \mathrm{X}$.

Fig. 2a shows the stress/strain curve of an austenitic stainless steel specimen for which SEM images were obtained at various target deformation locations as noted on the graph. This specimen was cold rolled, $40 \mathrm{~mm}$ in length and had $1 \mathrm{~mm}^{2}$ cross sectional area, and its surface was mechanically polished. Originally the sample was flat with no slip bands, but when stress was applied the grains were distorted and elongated. This grain elongation is seen in the SEM images in Fig. $2 b$, and a marker is placed to follow the same grain through subsequent deformation. Prior to rupture, necking occurred and grain boundaries were hard to distinguish because the grains were heavily distorted and had developed significant slip planes. Figure 3 shows the EDS to investigate impurities in a crack region.

Fig. 4 shows a continuous fiber polymeric composite specimen made of vinyl ester resin and carbon fiber $(\mathrm{CF} / \mathrm{VE})$ before and after fracture. A typical fracture surface for a specimen with 45 degree fiber orientation caused by fracture resulting from interfacial debonding in the carbon fiber/vinyl ester can be seen. The cracks tend to run along the matrix between the fibers which indicate a brittle microstructure for the composite specimen.

Ongoing research includes the use of EBSD technique to evaluate the grain level deformation as a function of external stress.

\section{$\underline{\text { References }}$}

[1] J.X. Li, W.Y. Chu, Y.B. Wang, L.J. Qiao, In-situ TEM study of stress corrosion cracking of austenitic stainless steel, Corrosion Science 45 (2003) 1355-1365

[2] Z.Z. Yuan, Q.X. Dai, X.N. Cheng, K.M. Chen, L. Pan, A.D. Wang, In-situ SEM tensile test of high-nitrogen austenitic stainless steels, Materials Characterization 56 (2006) 79-83 


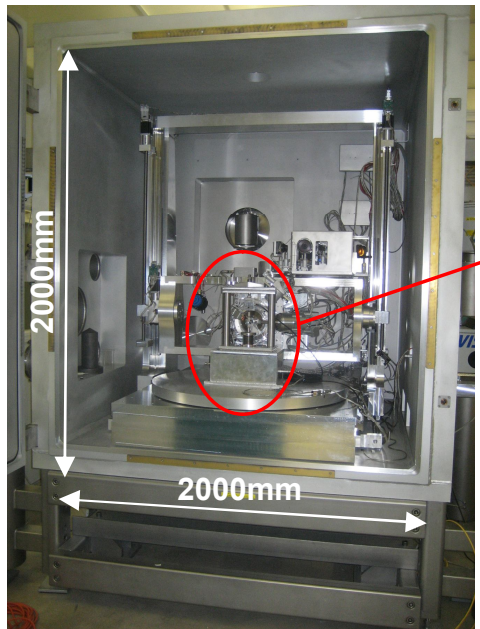

Fig. 1: a) LC-SEM with

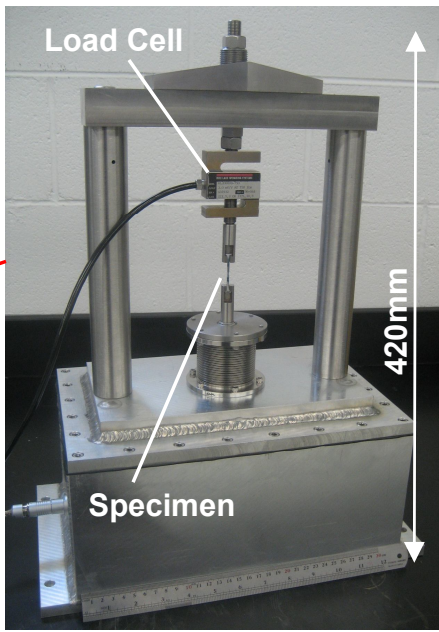

b) Testing System

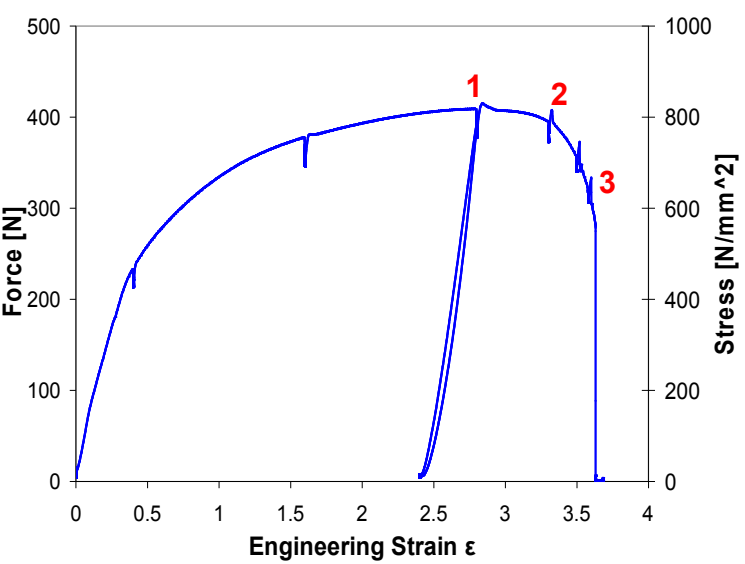

Fig. 2a: Stress versus Engineering Strain graph
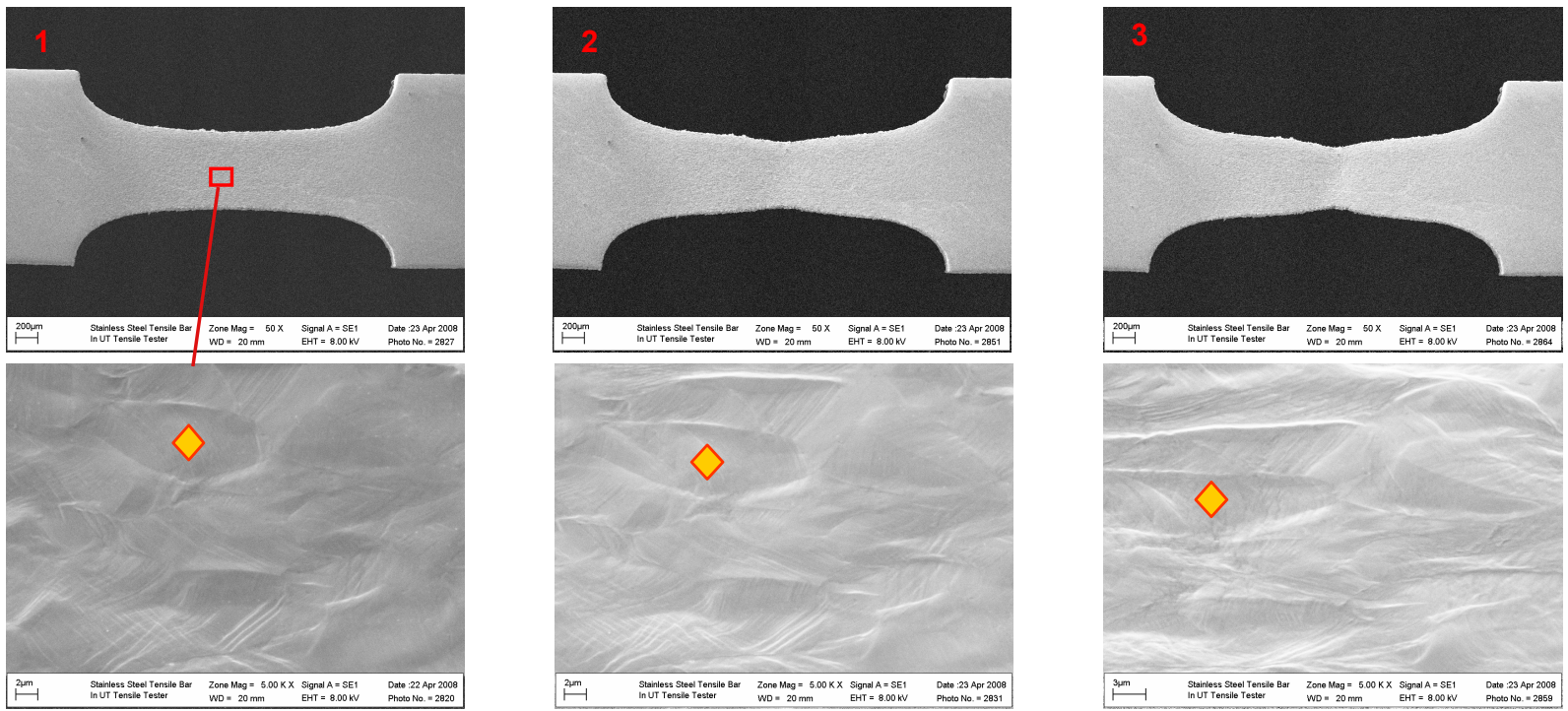

Fig. 2b: Images taken at various deformations in different magnifications (1st row 50x: Scale bar $=200 \mu \mathrm{m} \&$ 2nd row 5000x: Scale bar $=2 \mu \mathrm{m}$ ) acquired with SE-detector, electron beam accelerating voltage $=8 \mathrm{kV}$

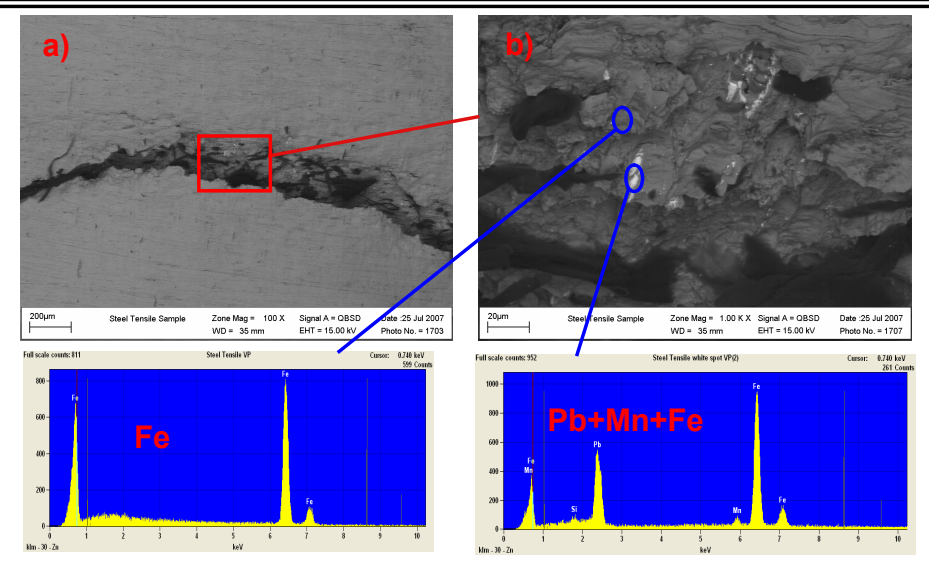

Fig. 3: EDS analysis in crack area to analyze impurities; SEM images obtained with BSE-detector (electron beam accelerating voltage $=15 \mathrm{kV}$ ) a) $100 \mathrm{x}$ : Scale bar $=200 \mu \mathrm{m}$; b) 1000x: Scale bar $=20 \mu \mathrm{m}$
Fig. 4: Gage area of a carbon fiber/vinyl ester specimen after failure (BSEdetector, electron beam accelerating voltage $=20 \mathrm{kV}$ ) a) 125x: Scale bar $=200 \mu \mathrm{m}$

b) 1000x: Scale bar $=20 \mu \mathrm{m}$ (individual fractured fibers from matrix can be viewed)
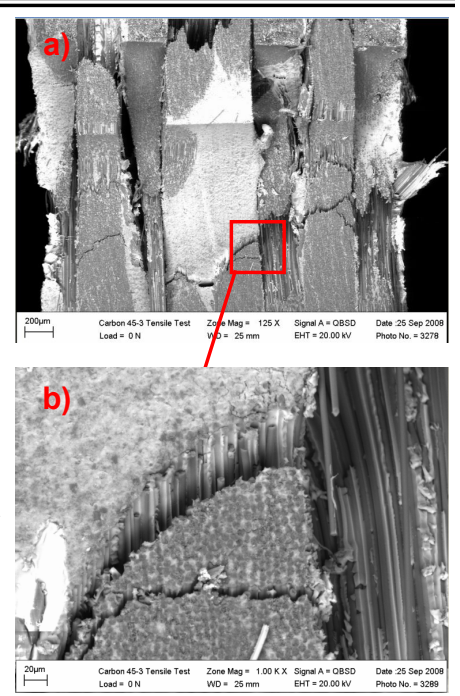